\title{
Avaliação de Diferentes Híbridos de Sorgo (Sorghum bicolor, L. Moench) quanto aos Componentes da Planta e Silagens Produzidas ${ }^{1}$
}

\author{
Mikael Neumann², João Restle ${ }^{3}$, Dari Celestino Alves Filho ${ }^{4}$, Regis Augusto Carvalho \\ Bernardes $^{5}$, Miguelangelo Ziegler Arboite ${ }^{6}$, Liliane Cerdótes ${ }^{6}$, Luiz Antero de Oliveira Peixoto ${ }^{7}$
}

RESUMO - O experimento foi conduzido com o objetivo de avaliar as características qualitativas dos componentes da planta e da silagem e as características de fermentação da silagem de diferentes híbridos de sorgo forrageiros AGX-213 e AG-2002 e de duplo propósito AGX-217 e AG-2005E. O componente panícula apresentou maiores teores de matéria seca (MS), proteína bruta (PB), matéria mineral (MM) e digestibilidade in vitro da matéria seca (DIVMS) e menores teores dos constituintes da parede celular da planta com relação aos componentes colmo e folhas. Não houve diferenças entre as silagens dos híbridos de sorgo para os teores de MM e DIVMS. A silagem do AG-2005E apresentou maior teor de MS (35,50\%), PB (6,69\%), extrato etéreo (2,28\%) e extrativos não-nitrogenados (58,56\%) frente aos demais genótipos. Não houve diferença entre as silagens para os teores de nitrogênio insolúvel na FDA. As silagens de híbridos de sorgo forrageiro (AGX-213 e AG-2002) apresentaram menor $\mathrm{pH}$ e teor de $\mathrm{N}_{-} \mathrm{NH}_{3}$ (\% do N total) em comparação aos híbridos de duplo propósito (AGX-217 e AG-2005E).

Palavras-chave: colmo, folhas, panícula, silagem, sorgo forrageiro, sorgo duplo propósito

\section{Evaluation of Different Sorghum Hybrids (Sorghum bicolor, L. Moench) Related to Plant Components and Produced Silages}

\begin{abstract}
The experiment was conducted with the purpose to evaluate the qualitative traits of the plant components and fermentation characteristics of silages from different sorghum hybrids AGX-213, AG-2002 (forage) and AGX-217, AG-2005E (double purpose). The panicle component showed higher percentages of dry matter (DM), crude protein (CP), mineral material (MM) and in vitro dry matter digestibility (IVDMD), and lower percentages of plant cell wall than the stems and leaves. No differences were observed among the sorghum silages for MM and IVDMD percentages. The AG-2005E silage showed higher contents of DM (35.5\%), CP (6.69\%), ether extract (2.28\%) and nitrogen-free extract (58.56\%) in comparison with the other genotypes. No difference was observed among the sorghum silages for acid detergent insoluble nitrogen (ADIN) content. The silages of the forage hybrids (AGX-213 and AG-2002) showed lower $\mathrm{pH}$ and $\mathrm{N}-\mathrm{NH}_{3}(\%$ of total $\mathrm{N}$ ) in comparison with the double purpose (AGX-217 and AG-2005E) hybrids.
\end{abstract}

Key Words: double purpose sorghum, forage sorghum, leaves, panicle, silage, stem

\section{Introdução}

A cultura do sorgo para produção de silagem no Rio Grande do Sul tem se mostrado como uma alternativa viável aos produtores rurais, principalmente em regiões com particularidades edafo-climáticas que limitam o cultivo e/ou o potencial produtivo da cultura do milho.

Nos últimos anos, foram introduzidos diversos híbridos de sorgo no mercado. Há, no entanto, poucas informações técnicas sobre suas características agro- nômicas produtivas e qualitativas, ou, ainda, sua indicação de melhor eficiência de uso nos diversos sistemas de produção de bovinos de corte existentes no estado. Segundo Silva et al. (1999c), existem poucas informações relativas às características de rendimento, composição morfológica e valor nutritivo das diversas variedades e/ou híbridos de sorgo mais adequadas à ensilagem.

O sorgo (Sorghum bicolor, L. Moench) é uma planta adaptada ao processo de ensilagem, devido às suas características fenotípicas que determinam fa-

\footnotetext{
${ }_{1}$ Parte da Dissertação de Mestrado do primeiro autor. Pesquisa parcialmente financiada pela FAPERGS.

2 Eng ${ }^{\circ}-$ Agr $^{\circ}$, MSc.

3 Engo-Agr ${ }^{\circ}$, Ph.D., Pesquisador do CNPq, Professor Titular do Departamento de Zootecnia da UFSM - Campus Camobi, 97119-900, Santa Maria - RS E.mail: jorestle@ccr.ufsm.br

4 Eng ${ }^{\circ}$-Agro, MSc., Professor do Departamento de Zootecnia da UFSM. E.mail: dcafilho@ccr.ufsm.br

5 Zootecnista, MSc., Professor do Departamento de Zootecnia da UFSM. E.mail: racber@ccr.ufsm.br

6 Zootecnista, Aluno de Mestrado em Zootecnia da UFSM.

7 Bolsista PIBIC-CNPq, Aluno do curso de Medicina Veterinária da UFSM.
} 
cilidade de plantio, manejo, colheita e armazenamento. No entanto, conforme Bruno et al. (1989), a produção de silagem de alta qualidade depende, entre outros fatores, primordialmente do rendimento de matéria seca por unidade de área, associado a boas características nutritivas das porções constituintes da planta.

Conceitos mais modernos de programas de melhoramento objetivam explorar o máximo possível o banco genético da cultura de sorgo, buscando selecionar materiais com qualidade de colmo e folhas, visando aumentar o valor nutritivo da planta. Segundo Van Soest (1994), a qualidade da silagem também é afetada, entre outros fatores, pelo processo fermentativo da massa, pois, durante a ensilagem, pode ocorrer redução do valor nutritivo pela respiração das partículas picadas, fermentação aeróbica, processos de decomposição ou perdas por efluentes. Entre os parâmetros que ajudam a definir boa fermentação, o pH e a concentração de nitrogênio amoniacal $\left(\mathrm{N}-\mathrm{NH}_{3} / \mathrm{NT}\right)$ são bons indicadores, pois determinam de forma prática a identificação de silagens de baixo consumo e as de boa aceitabilidade pelos animais (Elizalde, 1995).

Os híbridos de sorgo AG-2002 e AG-2005E encontram-se no mercado há vários anos. Já os híbridos AGX-213 e AGX-217 foram recentemente lançados pela empresa de melhoramento para suprir as necessidades dos produtores com relação a materiais com melhores características para produção de silagem de boa qualidade, visando substituir os materiais mais antigos.

Este trabalho foi realizado com o objetivo de avaliar as características químico-bromatológicas da planta e da silagem, assim como as características fermentativas da silagem de híbridos de sorgo de caráter forrageiro ou de duplo propósito.

\section{Material e Métodos}

Oexperimento foiconduzidono Setor deBovinocultura de Corte do Departamento de Zootecnia da Universidade Federal de Santa Maria, localizado fisiograficamente na Depressão Central do Estado do Rio Grande do Sul, a uma altitude de $95 \mathrm{~m}$. Cartograficamente, se localiza a 29०43' de latitude Sul e 5342' de longitude Oeste. O clima da região é o Cfa (subtropical úmido), conforme classificação de Köppen, com precipitação média anual de $1.769 \mathrm{~mm}$, temperatura média anual de $19,2^{\circ} \mathrm{C}$, média mínima de $9,3^{\circ} \mathrm{C}$ em julho e média máxima de $24,7^{\circ} \mathrm{C} \mathrm{em}$ janeiro, insolação de 2.212 horas anuais e umidade relativa do ar de $82 \%$ (Moreno, 1961).

R. Bras. Zootec., v.31, n.1, p.302-312, 2002 (suplemento)
O solo da área experimental é classificado como Podzólico vermelho-amarelo e pertence à unidade de mapeamento São Pedro. A unidade caracteriza-se por apresentar solos de textura superficial arenosa e friável, sendo naturalmente ácidos, pobres em matéria orgânica e, na maioria dos nutrientes, com baixa saturação de bases (Brasil, 1973).

O trabalho de pesquisa compreendeu o período de 21 de novembro de 1998 a 15 de agosto de 1999. Foram avaliados quatro híbridos de sorgo de comportamento agronômico diferenciado: AGX-213 (classificado como um híbrido forrageiro de porte intermediário); AG-2002 (híbrido forrageiro de porte alto); AGX-217 e o AG-2005E (híbridos de duplo propósito de porte médio).

As silagens dos híbridos de sorgo avaliados foram produzidas em uma área delimitada de terras de 16 ha. As características de manejo e fertilidade de solo foram adequadas ao cultivo do sorgo (Sorghum bicolor, L. Moench), sendo 4 ha de lavoura para cada híbrido avaliado. As lavouras foram implantadas em 21-22/11/1998, em sistema de plantio direto na resteva da mistura forrageira aveia (Avena strigosa) e azevém (Lolium multiflorum), dessecada com Glifosato + Óleo Mineral. A plantadeira utilizada foi regulada com espaçamento entre linhas de $1 \mathrm{~m}$, profundidade de semeadura de $1 \mathrm{~cm}$ e distribuição de 16 a 18 sementes por metro linear. A adubação de base foi constituída de $300 \mathrm{~kg} / \mathrm{ha}$ de fertilizante NPK, na formulação 10-20-20 (N-P $\left.2 \mathrm{O}_{5}-\mathrm{K}_{2} \mathrm{O}\right)$, conforme as CFRS/SC (1995), e em cobertura, 50 dias após o plantio, foram aplicados $150 \mathrm{~kg} / \mathrm{ha}$ de uréia. A condução das lavouras de sorgo não envolveu práticas agronômicas de controle de plantas daninhas e enfermidades com produtos químicos ou práticas culturais.

As lavouras foram colhidas conforme recomendações sugeridas por Demarchi (1993), ou seja, o momento de ensilagem das plantas de sorgo de caráter duplo propósito (AGX-217 e AG-2005E) foi determinado entre os estádios reprodutivos de grão pastoso a farináceo, enquanto o das plantas de sorgo de caráter forrageiro (AGX-213 e AG-2002), entre os estádios de grão farináceo a duro. O corte das plantas para o processo de ensilagem foi realizado com o auxílio de uma ensiladeira regulada com tamanho médio de picado de $1 \mathrm{~cm}$ e altura de corte média de $20 \mathrm{~cm}$. O material colhido foi transportado da área de cultivo, depositado em um local previamente nivelado e bem drenado, compactado com auxílio de um trator, em sistema de silos de superfície de armazenamento 
do tipo "torta", sendo vedados e protegidos com lona de polietileno de três camadas.

$\mathrm{Na}$ ocasião da colheita para ensilagem, procedeu-se à coleta de seis amostras ao acaso de plantas inteiras (material original) para cada híbrido de sorgo avaliado, cortadas manualmente a $20 \mathrm{~cm}$ do solo. Cada amostra constituiu-se de $4 \mathrm{~m}$ lineares na linha de plantio. A adoção dessa prática permitiu, além de estimar o potencial produtivo dos híbrido avaliados, determinar a estrutura física percentual das estruturas anatômicas da planta de sorgo, por intermédio da fragmentação das partes constituintes da planta em colmo, folhas e panícula.

A abertura dos silos tipo torta ocorreu, em média, 43 dias após a confecção da silagem. Cada silagem foi amostrada de forma homogênea e representativa, em três partes dos silos pré-determinadas (parte inicial, intermediária e final) e, assim como as amostras dos componentes físico-estruturais da planta (colmo, folhas e panícula), foram pesadas e pré-secas em estufa de ar forçado a $60^{\circ} \mathrm{C}$ por 72 horas. Após, foram retiradas da estufa e pesadas novamente para determinação do teor de matéria parcialmente seca, sendo seqüencialmente processadas em moinho tipo Willey, com peneira de malha de $1 \mathrm{~mm}$.

Nas amostras pré-secas, determinaram-se a matéria seca total (MS), em estufa a $105^{\circ} \mathrm{C}$, e o nitrogênio total (NT), pelo método micro Kjeldahl, sendo multiplicado pelo fator 6,25 para obtenção dos teores de proteína bruta $(\mathrm{PB})$, extrato etéreo (EE), fibra bruta (FB) e matéria mineral (MM), por incineração a $550^{\circ} \mathrm{C}$; de matéria orgânica (MO), por diferença $(\% \mathrm{MO}=100-\mathrm{MM})$, e extrativos não-nitrogenados $(\mathrm{ENN}=100$ - PB - FB - EE - MM), conforme AOAC (1984). A digestibilidade in vitro da matéria seca (DIVMS) foi determinada conforme técnica descrita por Tilley \& Terry (1963).

Para os componentes físicos da planta, determinaram-se os teores de fibra em detergente neutro (FDN), conforme Goering \& Van Soest (1970), e fibra em detergente ácido (FDA), hemicelulose $(\mathrm{HEM}=\mathrm{FDN}-\mathrm{FDA})$, celulose $(\mathrm{CEL}=\mathrm{FDA}-(\mathrm{LIG}+\mathrm{CZ}))$ e lignina + conteúdo de sílica da FDA $(\mathrm{LIG}+\mathrm{CZ})$, segundo AOAC (1995).

Amostras de silagem, na forma in natura, foram trituradas e utilizadas para análise do $\mathrm{pH}$, por intermédio de potenciômetro digital (Digimed), e do nitrogênio amoniacal, como porcentagem do nitrogênio total $\left(\mathrm{N}-\mathrm{NH}_{3} / \mathrm{NT}\right)$, conforme técnica descrita pela AOAC (1995).

R. Bras. Zootec., v.31, n.1, p.302-312, 2002 (suplemento)
O delineamento experimental foi o inteiramente casualizado, composto por quatro tratamentos (silagem de híbridos de sorgo: AGX-213, AG-2002, AGX-217 e AG-2005E), com seis repetições para o material original e três repetições para as silagens. Os dados coletados para cada parâmetro foram submetidos à análise de variância, por intermédio do programa estatístico SAS (1993), e as diferenças entre as médias foram analisadas pelo teste de Tukey a $5 \%$.

O modelo estatístico utilizado foi o seguinte:

$$
\mathrm{Y}_{\mathrm{ij}}=\mathrm{m}+\mathrm{SS}_{\mathrm{i}}+\mathrm{E}_{\mathrm{ij}}
$$

em que $Y_{i j}=$ variáveis dependentes; $m=$ média das observações; $\mathrm{SS}_{\mathrm{i}}=$ efeito da silagem de sorgo de ordem "i", sendo 1 (silagem de sorgo AGX-213), 2 (silagem de sorgo AG-2002), 3 (silagem de sorgo AGX-217) e 4 (silagem de sorgo AG-2005E); e $\mathrm{E}_{\mathrm{ij}}=$ erro aleatório, assumindo distribuição normal média igual a zero e variância $\sigma^{2}$.

\section{Resultados e Discussão}

Na Tabela 1 são apresentados os teores de matéria seca (MS), proteína bruta (PB), matéria orgânica (MO) e digestibilidade in vitro da matéria seca (DIVMS) dos componentes colmo, folhas e panícula, de acordo com o híbrido de sorgo testado.

Os teores de MS no componente colmo no momento da ensilagem foram semelhantes $(\mathrm{P}>0,05)$ entre os híbridos AG-2002 (29,05\%) e AGX-213 $(28,39 \%)$, diferindo $(\mathrm{P}<0,05)$ dos híbridos AGX-217 $(33,35 \%)$ e AG-2005E (23,04\%). Para os componentes folhas e panícula os teores de MS foram numericamente maiores nos híbridos de duplo propósito AG-2005E e AGX-217, comparados aos híbridos forrageiros AG-2002 e AGX-213.

$\mathrm{Na}$ análise dos componentes físico-estruturais da planta, todos os híbridos de sorgo apresentaram maiores teores de MS na fração panícula $(49,99 \%)$ em relação aos componentes folhas $(30,01 \%)$ e colmo $(28,46 \%)$. Comparando as partes físicas constituintes da planta de sorgo, observou-se que o teor de MS dos componentes folhas e colmo representou, respectivamente, 60,03 e $56,93 \%$ do teor de MS da panícula. Portanto, a panícula é o principal componente responsável pela definição do momento mais adequado para a colheita das plantas para ensilagem, independentemente do híbrido avaliado.

Segundo Zago (1991) e Pereira et al. (1993), o teor de MS eleva-se mais rapidamente em híbridos de sorgo de portes médio ou baixo, em função da maior 
Tabela 1 - Teores de matéria seca (MS), proteína bruta (PB), matéria orgânica (MO) e digestibilidade in vitro da matéria seca (DIVMS) dos componentes físicos estruturais da planta, de acordo com o híbrido de sorgo

Table 1 - Contents of dry matter (DM), crude protein (CP), organic matter (OM) and in vitro dry matter digestibility (IVDMD) of plant physical components, according to the sorghum hybrid

\begin{tabular}{|c|c|c|c|c|c|}
\hline \multirow[t]{2}{*}{$\begin{array}{l}\text { Estrutura da planta } \\
\text { Structure of plant }\end{array}$} & \multirow[t]{2}{*}{$\begin{array}{l}\text { Híbridos de sorgo } \\
\text { Sorghum hybrids }\end{array}$} & \multicolumn{4}{|c|}{$\begin{array}{l}\text { Parâmetros avaliados } \\
\text { Evaluated parameters }\end{array}$} \\
\hline & & $\begin{array}{l}\text { MS (\%) } \\
D M(\%)\end{array}$ & $\begin{array}{l}\text { PB }(\% \text { na } \mathrm{MS}) \\
C P(\% \text { of } D M)\end{array}$ & $\begin{array}{c}\mathrm{MO}(\% \text { na } \mathrm{MS}) \\
O M(\% \text { of } D M)\end{array}$ & $\begin{array}{l}\text { DIVMS (\%) } \\
\text { IVDMD (\%) }\end{array}$ \\
\hline \multirow{3}{*}{$\begin{array}{l}\text { Colmo } \\
\text { Stem }\end{array}$} & AGX-213 & $28,39^{\mathrm{b}}$ & $2,05^{\mathrm{ab}}$ & $97,93^{\mathrm{a}}$ & $57,73^{\mathrm{ab}}$ \\
\hline & $\begin{array}{l}\text { AG-2002 } \\
\text { AGX-217 } \\
\text { AG-2005E }\end{array}$ & $\begin{array}{l}29,05^{\mathrm{b}} \\
33,35^{\mathrm{a}} \\
23,04^{\mathrm{c}}\end{array}$ & $\begin{array}{l}2,84^{\mathrm{a}} \\
1,41^{\mathrm{b}} \\
1,54^{\mathrm{b}}\end{array}$ & $\begin{array}{l}97,42^{\mathrm{a}} \\
97,25^{\mathrm{a}} \\
95,10^{\mathrm{b}}\end{array}$ & $\begin{array}{c}62,47^{\mathrm{a}} \\
53,9^{\mathrm{b}} \\
54,77^{\mathrm{b}}\end{array}$ \\
\hline & $\begin{array}{l}\text { Média } \\
\text { Mean }\end{array}$ & $28,46^{\mathrm{B}}$ & $1,96^{\mathrm{C}}$ & $96,93^{\mathrm{A}}$ & $57,22^{\mathrm{B}}$ \\
\hline \multirow[t]{2}{*}{$\begin{array}{l}\text { Folhas } \\
\text { Leaves }\end{array}$} & $\begin{array}{c}\text { AGX-213 } \\
\text { AG-2002 } \\
\text { AGX-217 } \\
\text { AG-2005E }\end{array}$ & $\begin{array}{l}27,85^{\mathrm{bc}} \\
25,93^{\mathrm{c}} \\
35,23^{\mathrm{a}} \\
31,03^{\mathrm{b}}\end{array}$ & $\begin{array}{l}4,95^{\mathrm{b}} \\
6,72^{\mathrm{a}} \\
6,63^{\mathrm{a}} \\
3,50^{\mathrm{c}} \\
\end{array}$ & $\begin{array}{l}93,33^{\mathrm{a}} \\
94,77^{\mathrm{a}} \\
93,54^{\mathrm{a}} \\
94,00^{\mathrm{a}}\end{array}$ & $\begin{array}{l}55,08^{\mathrm{a}} \\
56,29^{\mathrm{a}} \\
53,18^{\mathrm{a}} \\
54,86^{\mathrm{a}}\end{array}$ \\
\hline & $\begin{array}{l}\text { Média } \\
\text { Mean }\end{array}$ & $30,01^{\mathrm{B}}$ & $5,45^{\mathrm{B}}$ & $93,91^{\mathrm{B}}$ & $54,85^{\mathrm{B}}$ \\
\hline \multirow[t]{2}{*}{$\begin{array}{l}\text { Panícula } \\
\text { Panicle }\end{array}$} & $\begin{array}{c}\text { AGX-213 } \\
\text { AG-2002 } \\
\text { AGX-217 } \\
\text { AG-2005E }\end{array}$ & $\begin{array}{c}45,72^{\mathrm{b}} \\
46,72^{\mathrm{b}} \\
51,79^{\mathrm{ab}} \\
55,74^{\mathrm{a}}\end{array}$ & $\begin{array}{c}7,04 \mathrm{c} \\
9,25^{\mathrm{a}} \\
7,36^{\mathrm{b}} \\
6,84^{\mathrm{d}}\end{array}$ & $\begin{array}{l}97,72^{\mathrm{a}} \\
98,08^{\mathrm{a}} \\
98,25^{\mathrm{a}} \\
97,11^{\mathrm{a}}\end{array}$ & $\begin{array}{l}63,13^{\mathrm{b}} \\
71,77^{\mathrm{a}} \\
68,25^{\mathrm{a}} \\
69,64^{\mathrm{a}}\end{array}$ \\
\hline & $\begin{array}{l}\text { Média } \\
\text { Mean }\end{array}$ & $49,99^{\mathrm{A}}$ & $7,62^{\mathrm{A}}$ & $97,79^{\mathrm{A}}$ & $68,20^{\mathrm{A}}$ \\
\hline
\end{tabular}

a,b,c,d Médias, na coluna, seguidas de letras minúsculas diferentes, para cada variável, diferem a $5 \%$ pelo teste Tukey.

A,B,C Médias, na coluna, seguidas de letras maiúsculas diferentes, para cada componente da planta, diferem a $5 \%$ pelo teste Tukey.

$a, b, c, d$ Means, within a column, followed by different small letters, for each variable, are different $(P<.05)$ by Tukey test.

$A, B, C$ Means, within a column, followed by different capital letters, for each component of plant, are different $(P<.05)$ by Tukey test.

participação de panículas na matéria seca total. Este aspecto foi observado também no presente trabalho, no qual se observaram maiores teores de MS $(\mathrm{P}>0,05)$ para os híbridos de duplo propósito de porte médio (AG-2005E e AGX-217), comparados aos híbridos forrageiros de portes alto (AG-2002) e médio(AGX-213). Segundo Silva et al. (1999a), os teores de MS dos componentes da planta são variáveis conforme a interação genótipo/ambiente, atuando sobre o acúmulo de matéria seca da planta inteira.

Os teores de PB foram diferentes $(\mathrm{P}<0,05)$ entre os híbridos de sorgo no componente colmo. Maiores concentrações de PB foram observadas no híbrido forrageiro AG-2002 (2,84\%) em relação aos híbridos de duplo propósito AGX-217 (1,41\%) e AG-2005E $(1,54 \%)$. Entretanto, o teor de $\mathrm{PB}$ do híbrido forrageiro AGX-213 (2,05\%) foi semelhante $(\mathrm{P}>0,05)$ aos demais materiais. Para os componentes folhas e panícula, o teor de $\mathrm{PB}$ foi diferente $(\mathrm{P}<0,05)$ entre os híbridos de sorgo. Maiores teores de $\mathrm{PB}$ foram observados no componente folhas para os híbridos AG-2002 (6,72\%) e AGX-217 (6,63\%), diferindo estatisticamente dos híbridos AGX-213 (4,95\%) e AG-2005E (3,50\%). Já para o componente panícula, o híbrido AG-2002 $(9,25 \%)$ destacou-se com maiores $(\mathrm{P}<0,05)$ teores de PB em relação aos demais híbridos AGX-217 (7,36\%), AGX-213 (7,04\%) e AG-2005E (6,84\%). Na análise do teor de $\mathrm{PB}$ entre os componentes das estruturas anatômicas da planta, observou-se maior $(\mathrm{P}<0,05)$ teor de PB para o componente panícula $(7,62 \%)$ em relação aos componentes folhas $(5,45 \%)$ e colmo (1,96\%). Silva et al. (1999b), ao avaliarem os híbridos de sorgo BR-303 (granífero), CMSXS-756 (duplo propósito) e o BR-601 (forrageiro), verificaram que o incremento da participação de panícula na massa ensilada promoveu aumento progressivo no teor de PB da silagem para todos os híbridos, indicando que este componente apresenta maior teor de PB que o conjunto folhas +colmo. Já Bruno et al. (1989), trabalhando com híbridos de sorgo forrageiro de baixa produção de grãos para silagem, concluíram que os maiores conteúdos de PB, FDN, FDA e LIG se encontram na porção folhas e menores conteúdos, na porção colmo. 
O híbrido AG-2005E, no componente colmo, apresentou menor $(\mathrm{P}<0,05)$ teor de MO $(95,10 \%)$ em relação aos demais híbridos avaliados. Não foi observada diferença $(\mathrm{P}>0,05)$ para os teores de $\mathrm{MO}$ entre os híbridos de sorgo, nas frações folhas e panícula (Tabela 1). Na análise dos resultados médios entre os componentes estruturais da planta, maiores teores de MO $(\mathrm{P}<0,05)$ foram observados para os componentes panícula $(97,79 \%)$ e colmo $(96,93 \%)$, comparados ao componente folhas $(93,91 \%)$.

A DIVMS no componente colmo foi superior $(\mathrm{P}<0,05)$ para o híbrido forrageiro AG-2002 (62,47\%), comparado aos híbridos de duplo propósito AG-2005E (54,77\%) e AGX-217 (53,91\%). Na análise da DIVMS do componente folhas, não se constatou diferença $(\mathrm{P}>0,05)$ entre os genótipos testados. Quanto ao componente panícula, menor $(\mathrm{P}<0,05)$ DIVMS foi observada para o híbrido AGX-213 (63,13\%). Os demais materiais foram semelhantes $(\mathrm{P}>0,05)$, com DIVMS média de 69,89\%. Segundo Nussio (1995), a justificativa para que materiais de alta produção de grãos (híbridos graníferos e de duplo propósito) apresentem menor DIVMS no componente colmo tem respaldo no maior número de células de menor tamanho individual em sua estrutura, resultante de programas de melhoramento para maior resistência do colmo ao acamamento e agentes patogênicos. Para os resultados médios dos coeficientes da digestibilidade dos componentes físicos da planta observou-se maior DIVMS para porção panícula $(68,20 \%)$, diferindo $(\mathrm{P}<0,05)$ das porções colmo $(57,22 \%)$ e folhas (54,85\%). Evidencia-se que o componente panícula é o principal responsável pelos incrementos dos teores de MS, PB e DIVMS na silagem, bem como pelos decréscimos de FDN, FDA e LIG+CZ.

Os resultados do presente trabalho também demonstram a variabilidade dentro de cada componente da planta e entre os diferentes híbridos, sugerindo a possibilidade de melhoria da qualidade da silagem de sorgo, por intermédio de programas de melhoramento genético, visando à obtenção de genótipos com maiores teores de PB e DIVMS nas diferentes partes da planta.

De maneira geral, a variação encontrada nos resultados das análises bromatológicas dos híbridos avaliados sugere mais estudos nesta área, visando à recomendação e utilização mais correta possível dos diferentes materiais genéticos ofertados pelas empresas.

$\mathrm{Na}$ Tabela 2 são apresentados os teores médios dos constituintes da parede celular dos componentes estruturais da planta de sorgo.
Analisando os teores dos constituintes da parede celular da fração colmo, verifica-se que o híbrido AG-2002 apresentou o menor valor $(\mathrm{P}<0,05) \mathrm{de}$ FDN, FDA, CEL e LIG $+\mathrm{CZ}$, frente aos demais, indicando melhor qualidade de colmo. O teor de HEM no componente colmo do híbrido AGX-217 (31,46\%) foi superior $(\mathrm{P}<0,05)$ em relação aos demais híbridos.

No componente folhas, o teor de FDN foi superior $(\mathrm{P}<0,05)$ para o híbrido AGX-217 $(75,83 \%)$ em relação ao AG-2002 (71,06\%), AG-2005E (68,50\%) e AGX-213 (68,39\%). O maior $(\mathrm{P}<0,05)$ teor de FDA foi observado no híbrido AG-2005E (47,19\%), diferindo dos híbridos AGX-217 (43,04\%), AG-2002 (41,72\%) e AGX-213 (37,04\%). O teor de HEM no componente folhas do híbrido AG-2005E (21,32\%) foi menor $(\mathrm{P}<0,05)$ em relação aos híbridos AGX-217 (32,79\%), AGX-213 (31,35\%) e AG-2002 (29,34\%). Maiores teores de CEL $(\mathrm{P}<0,05)$ foram observados no componente folhas para os híbridos de duplo propósito AG-2005E $(36,61 \%)$ e AGX-217 (35,03\%), frente aos híbridos forrageiros AG-2002 (32,38\%) e AGX-213 (29,39\%). Já para o teor de $L I G+C Z$ não foi observada diferença $(\mathrm{P}>0,05)$ entre os diferentes híbridos de sorgo.

Para o componente panícula, os teores de FDN, FDA, HEM, CEL e LIG $+\mathrm{CZ}$, diferiram $(\mathrm{P}<0,05)$ entre os híbridos de sorgo, apresentando variação de 22,42 a 39,$30 ; 6,88$ a 14,$79 ; 15,54$ a 24,$51 ; 5,27$ a 10,35 ; e 1,61 a $4,68 \%$, respectivamente. Numericamente, o híbrido AG-2005E apresentou os maiores valores para os teores de FDN $(39,30 \%)$, FDA $(14,79 \%)$ e LIG+CZ (4,68\%) no componente panícula, em relação aos demais híbridos avaliados.

Os resultados médios para os constituintes da parede celular dos componentes da planta demonstram que o componente panícula apresentou os menores teores de FDN, FDA, HEM, CEL e LIG+CZ, comparado aos componentes colmo e folhas, caracterizando-se como a porção da planta de maior valor nutritivo, bem como a determinante para obtenção e manutenção da qualidade da massa ensilada.

Ponderações semelhantes foram relatadas por Nussio (1992), o qual, ao trabalhar com híbridos de milho para produção de silagem, observou que materiais precoces com maior porcentagem de grãos na MS tenderam a apresentar maior teor de FDN no colmo.

Observa-se, nas Tabelas 1 e 2, que o híbrido AG-2002 apresenta pronunciada qualidade de colmo, pela maior DIVMS $(62,47 \%)$ e pelos menores teores de $\operatorname{FDN}(52,32 \%)$, FDA $(30,10 \%)$, CEL $(24,59 \%)$ e 
Tabela 2 - Teores de fibra em detergente neutro (FDN), fibra em detergente ácido (FDA), hemicelulose (HEM), celulose (CEL) e lignina + cinzas da FDA ( $L I G+C Z)$ dos componentes colmo, folhas e panícula, de acordo com o híbrido de sorgo

Table 2 - Contents of neutral detergent fiber (NDF), acid detergent fiber (ADF), hemicellulose (HEM), cellulose (CEL) and lignin+total ash $(L I G+T A)$ of stem, leaves and panicle, according to the sorghum hybrid

\begin{tabular}{|c|c|c|c|c|c|c|}
\hline \multirow[t]{2}{*}{$\begin{array}{l}\text { Estrutura da planta } \\
\text { Structure of plant }\end{array}$} & \multirow[t]{2}{*}{$\begin{array}{l}\text { Híbridos de sorgo } \\
\text { Sorghum hybrids }\end{array}$} & \multicolumn{5}{|c|}{$\begin{array}{l}\text { Constituintes da parede celular, \% MS } \\
\text { Compounds of plant cellular wall, \% DM }\end{array}$} \\
\hline & & $\begin{array}{l}\text { FDN } \\
N D F\end{array}$ & $\begin{array}{l}\mathrm{FDA} \\
A D F\end{array}$ & $\begin{array}{l}\text { HEM } \\
H E M\end{array}$ & $\begin{array}{l}\text { CEL } \\
C E L\end{array}$ & $\begin{array}{l}\mathrm{LIG}+\mathrm{CZ} \\
L I G+T A \\
\end{array}$ \\
\hline \multirow[t]{2}{*}{$\begin{array}{l}\text { Colmo } \\
\text { Stem }\end{array}$} & $\begin{array}{c}\text { AGX-213 } \\
\text { AG-2002 } \\
\text { AGX-217 } \\
\text { AG-2005E }\end{array}$ & $\begin{array}{l}60,84^{\mathrm{b}} \\
52,32^{\mathrm{c}} \\
73,23^{\mathrm{a}} \\
70,75^{\mathrm{a}}\end{array}$ & $\begin{array}{l}37,04^{\mathrm{c}} \\
30,10^{\mathrm{d}} \\
41,77^{\mathrm{b}} \\
45,31^{\mathrm{a}}\end{array}$ & $\begin{array}{l}23,80^{\mathrm{b}} \\
22,22^{\mathrm{b}} \\
31,46^{\mathrm{a}} \\
25,44^{\mathrm{b}}\end{array}$ & $\begin{array}{l}30,41^{\mathrm{b}} \\
24,59^{\mathrm{c}} \\
34,57^{\mathrm{a}} \\
35,14^{\mathrm{a}}\end{array}$ & $\begin{array}{c}6,64^{\mathrm{b}} \\
5,51^{\mathrm{c}} \\
7,20^{\mathrm{b}} \\
10,15^{\mathrm{a}}\end{array}$ \\
\hline & $\begin{array}{l}\text { Média } \\
\text { Mean }\end{array}$ & $64,29^{B}$ & $38,56^{\mathrm{A}}$ & $25,73^{A}$ & $31,18^{\mathrm{A}}$ & $7,38^{\mathrm{A}}$ \\
\hline \multirow[t]{2}{*}{$\begin{array}{l}\text { Folhas } \\
\text { Leaves }\end{array}$} & $\begin{array}{l}\text { AGX-213 } \\
\text { AG-2002 } \\
\text { AGX-217 }\end{array}$ & $\begin{array}{c}68,39^{b} \\
71,06^{b} \\
75,83^{a}\end{array}$ & $\begin{array}{l}37,04^{\mathrm{c}} \\
41,72^{\mathrm{b}} \\
43,04^{\mathrm{b}}\end{array}$ & $\begin{array}{l}31,35^{\mathrm{a}} \\
29,34^{\mathrm{a}} \\
32,79^{\mathrm{a}}\end{array}$ & $\begin{array}{l}29,39^{c} \\
32,38^{b} \\
35,03^{a}\end{array}$ & $\begin{array}{l}7,64^{\mathrm{a}} \\
9,35^{\mathrm{a}} \\
8,01^{\mathrm{a}}\end{array}$ \\
\hline & $\begin{array}{c}\text { AG-2005E } \\
\text { Média } \\
\text { Mean }\end{array}$ & $\frac{68,50^{\mathrm{b}}}{70,95^{\mathrm{A}}}$ & $\frac{47,19^{\mathrm{a}}}{42,25^{\mathrm{A}}}$ & $\frac{21,32^{\mathrm{b}}}{28,70^{\mathrm{A}}}$ & $\frac{36,61^{\mathrm{a}}}{33,35^{\mathrm{A}}}$ & $\frac{10,59^{\mathrm{a}}}{8,90^{\mathrm{A}}}$ \\
\hline \multirow[t]{2}{*}{ Panicle } & $\begin{array}{l}\text { AGX-213 } \\
\text { AG-2002 } \\
\text { AGX-217 } \\
\text { AG-2005E }\end{array}$ & $\begin{array}{c}30,05^{\mathrm{b}} \\
30,88^{\mathrm{b}} \\
22,42^{\mathrm{c}} \\
39,30^{\mathrm{a}}\end{array}$ & $\begin{array}{c}14,10^{\mathrm{a}} \\
10,10^{\mathrm{b}} \\
6,88^{\mathrm{c}} \\
14,79^{\mathrm{a}}\end{array}$ & $\begin{array}{l}15,95^{\mathrm{b}} \\
20,78^{\mathrm{a}} \\
15,54^{\mathrm{b}} \\
24,51^{\mathrm{a}}\end{array}$ & $\begin{array}{c}10,35^{\mathrm{a}} \\
5,63^{\mathrm{b}} \\
5,27^{\mathrm{b}} \\
10,11^{\mathrm{a}}\end{array}$ & $\begin{array}{c}3,75^{\mathrm{b}} \\
4,47^{\mathrm{ab}} \\
1,61^{\mathrm{c}} \\
4,68^{\mathrm{a}}\end{array}$ \\
\hline & $\begin{array}{l}\text { Média } \\
\text { Mean }\end{array}$ & $30,66^{\mathrm{C}}$ & $11,47^{\mathrm{B}}$ & $19,19^{\mathrm{B}}$ & $7,84^{\mathrm{B}}$ & $3,63^{\mathrm{B}}$ \\
\hline
\end{tabular}

a,b,c,d Médias, na coluna, seguidas de letras minúsculas diferentes, para cada variável, diferem a $5 \%$ pelo teste Tukey.

A,B,C Médias, na coluna, seguidas de letras maiúsculas diferentes, para cada componente da planta, diferem a $5 \%$ pelo teste Tukey.

$a, b, c, d \quad$ Means, within a column, followed by different small letters, for each variable, are different $(P<.05)$ by Tukey test.

$A, B, C \quad$ Means, within a column, followed by different capital letters, for each component of plant, are different $(P<.05)$ by Tukey test.

LIG+CZ (5,51\%). Contudo, esta proporcionalidade não foi suficiente para compensar a qualidade do volumoso na forma de silagem comparado aos demais materiais avaliados, o que pode ser explicado pela baixa participação do componente panícula $(24,3 \%)$ na estrutura física da planta inteira, com base na matéria seca. Este fator é também observado em milho, sendo que Almeida Filho et al. (1999), avaliando as características agronômicas de cultivares desta planta, verificaram que a maior proporção de espigas em relação à planta inteira realça a qualidade e o valor nutritivo da forragem e da silagem resultante, sendo considerada a principal estrutura responsável pelo incremento dos valores de DIVMS e decréscimo dos teores de FDN e FDA.

O presente trabalho demonstra que mais estudos devem ser realizados nesta área, visando selecionar materiais com melhor qualidade de colmo e de folhas, pois, além da porcentagem de grãos na massa ensilada, os teores dos constituintes da parede celular dos componentes da planta também contribuíram para definir o valor nutritivo final dos materiais na forma de silagem. Fica evidenciado que a existência de variabilidade genética observada entre os híbridos e em suas respectivas estruturas físicas da planta (Tabelas 1 e 2) servem de base para qualquer programa de seleção de variedades, quando se objetiva uma silagem de alta qualidade.

Os parâmetros relativos à qualidade das silagens avaliadas são apresentados na Tabela 3 .

Os teores de MS da silagem diferiram $(\mathrm{P}<0,05)$ entre os genótipos avaliados (Tabela 3 ), observando-se menores teores para os híbridos forrageiros AG-2002 (26,79\%) e AGX-213 (29,30\%) comparados aos de duplo propósito AGX-217 (32,62\%) e AG-2005E $(35,50 \%)$. Entre os parâmetros que ajudam a definir a manutenção da qualidade e estabilidade do processo fermentativo do material ensilado, o teor de MS da silagem, segundo Borges et al. (1997), permite classificar as silagens dos híbridos de sorgo AGX-217 e AG-2005E como de muito boa qualidade e as silagens dos híbridos forrageiros, de boa qualidade. 
O menor teor de MS da silagem do AG-2002 é justificado por ser um híbrido de colmo suculento com teor de MS no colmo de 29,05\% (Tabela 1) e apresentar elevada porção colmo na constituição da planta (56,8\%), enquanto os demais híbridos avaliados apresentaram maior participação de panícula na estrutura da planta.

Zago (1991) observou menor teor de MS para o AG-2002 (30,9\%), comparado ao AG-2005E (38,7\%), sendo que ambos os cultivares foram colhidos no estádio de grão farináceo. Da mesma forma, Silva et al. (1999a), trabalhando com híbridos de sorgo de comportamento granífero, duplo propósito e forrageiro, observaram teores de MS decrescentes de 37,80; 31,85 ; e $24,69 \%$, respectivamente, constatando que a panícula foi a fração que mais contribuiu para o aumento do teor de MS da planta e da respectiva silagem, resultados semelhantes aos obtidos no presente trabalho. Pesce et al. (2000a), trabalhando com 20 híbridos de portes médio e alto, não encontraram diferença entre os teores de MS das silagens analisadas, constatando que não houve relação entre os teores de MS e os teores de suculência de colmo. No entanto, os autores ressalvam que, nos sorgos, o teor de MS varia com a idade de corte e a natureza do colmo da planta.

O menor teor de MS da silagem do híbrido AG-2002 poderia ser corrigido retardando o momento da colheita, visto que o teor de MS ideal para ensilagem seria entre 30 e 35\% (Van Soest, 1994; Borges et al.,
1997; Pesce et al., 2000a), com o objetivo de evitar perdas de MS pela formação de efluentes e processos biológicos que produzam gases, água e calor, visando uma fermentação láctica adequada para manutenção do valor nutritivo da silagem. Porém, Pizarro (1979), trabalhando com híbridos de sorgo de caráter forrageiro e granífero, demonstraram que o efeito do avanço do estádio de maturação da planta decresce mais acentuadamente os coeficientes de digestibilidade da matéria seca em silagens de híbridos de baixo conteúdo de grãos (forrageiros) em relação a silagens de híbridos de alta produção de grãos (graníferos).

Demarchi et al. (1995) ressaltam que, no processo de maturação, do florescimento ao estádio de grãos duros, ocorrem alterações na composição química da planta, principalmente pela redução dos teores de PB e DIVMS das partes vegetativas colmo e folhas. Entretanto, a produção de nutrientes aumenta acentuadamente, principalmente em materiais genéticos de maior produção de grãos, em função da elevada translocação de nutrientes para a panícula. Segundo Zago (1991), das frações da planta de sorgo, o colmo é a porção que menos contribui para a elevação do teor de MS, seguido pelas folhas e panícula. Assim, o aumento na participação da panícula na estrutura física da planta torna-se o principal responsável pela alteração no teor de MS e conseqüente antecipação de colheita para ensilagem.

Os teores de $\mathrm{PB}$ diferiram $(\mathrm{P}<0,05)$ entre as

Tabela 3 - Teores médios de matéria seca (MS), proteína bruta (PB), matéria mineral (MM), extrato etéreo (EE), fibra bruta (FB), extrativos não nitrogenados (ENN) e digestibilidade in vitro da matéria seca (DIVMS) de silagens de diferentes híbridos de sorgo, com base na matéria seca total

Table 3 - Average contents of dry matter (DM), crude protein (CP), mineral matter (MM), ether extract (EE), crude fiber (CF), nitrogen-free extract (NFE) and in vitro dry matter digestibility (IVDMD) of silages of different sorghum hybrids, on the total dry matter basis

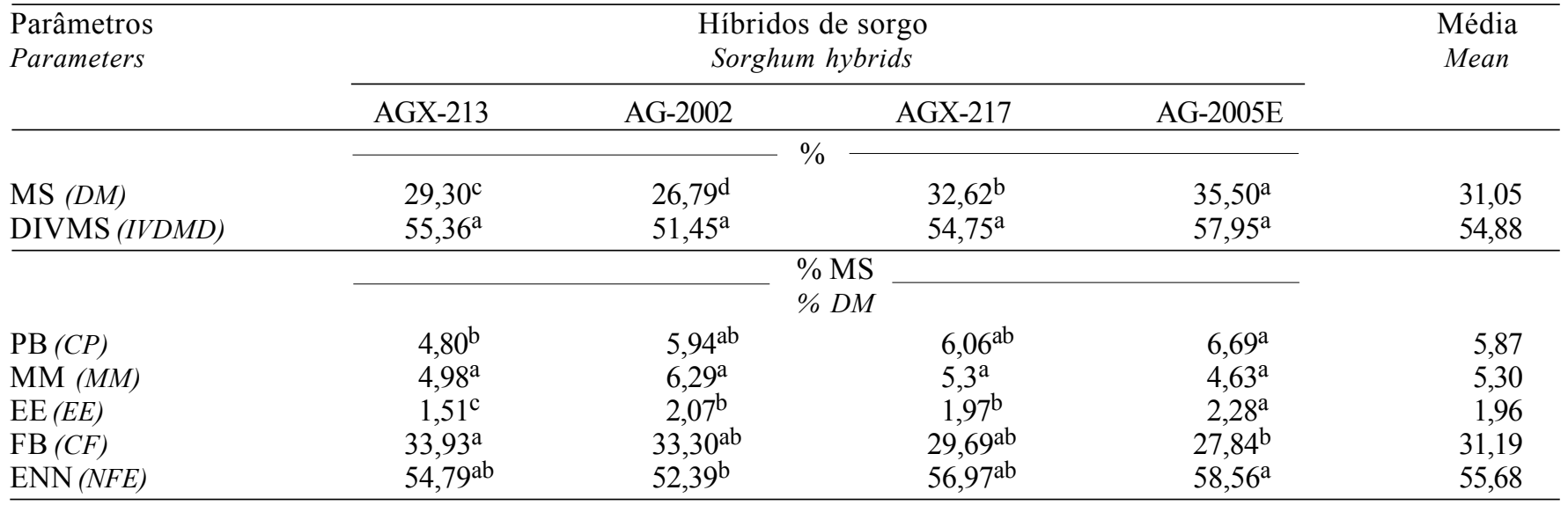

a,b,c,d Médias, na linha, seguidas por letras minúsculas diferentes, diferem entre si pelo teste de Tukey a $5 \%$.

$a, b, c, d \quad$ Means, within a row, followed by different small letters, are different $(P<.05)$ by Tukey test. 
silagens avaliadas, com valores variando de 4,80 a $6,69 \%$, sendo justificado pelas variações do teor de PB dos componentes colmo, folhas e panícula do híbridos testados (Tabela 1), assim como pela composição física da planta, pois o híbrido AG-2005E apresentou maior porcentagem de panícula $(58,4 \%)$ e baixa porcentagem de colmo $(20,1 \%)$ e folhas $(21,5 \%)$. Já os híbridos AG-2002 e AGX-213 apresentaram maiores proporções do componente colmo $(56,8$ e $45,1 \%)$ e menores proporções do componente panícula $(24,3$ e $24,6 \%$, respectivamente). Já o híbrido AGX-217 apresentou uma distribuição física percentual mais equilibrada dos componentes colmo $(36,3 \%)$, folhas $(32,4 \%)$ e panícula $(31,3 \%)$.

Silva et al. (1999c), trabalhando com silagem de híbridos de sorgo de portes baixo, médio e alto, com diferentes proporções do componente panícula na massa ensilada, observaram aumento progressivo do teor de PB na silagem com o aumento da participação da panícula na estrutura física da planta. Os mesmos autores também observaram que a silagem da planta inteira do híbrido de sorgo granífero apresentou maior teor de PB $(8,31 \%)$ que os híbridos duplo propósito $(7,45 \%)$ e forrageiro $(6,22 \%)$. Da mesma forma, o aumento da porcentagem de panícula nas silagens elevou significativamente a porcentagem de PB da mesma, indicando que a panícula tem maior teor de PB que o conjunto folhas +colmo. No presente trabalho, o teor de PB da silagem de híbridos de duplo propósito foi de $6,38 \%$, superior ao de caráter forrageiro com $5,37 \%$. Resultados semelhantes foram relatados por Silva et al. (1999b), demonstrando que os componentes folhas e panícula são as estruturas anatômicas da planta que apresentam maiores teores de PB.

Não houve diferença $(\mathrm{P}>0,05)$ no teor de $\mathrm{MM}$ da silagem dos híbridos de sorgo avaliados, com média de $5,30 \%$ (Tabela 3 ). Os teores de EE das silagens dos híbridos AGX-217 (1,97\%) e AG-2002 (2,07\%) foram semelhantes entre si, porém ambos diferiram $(\mathrm{P}<0,05)$ dos híbridos AGX-213 (1,51\%) e AG-2005E (2,28\%).

$\mathrm{O}$ teor de FB da silagem do híbrido AG-2002 $(33,93 \%)$ foi superior ao híbrido AG-2005E (27,84\%), sendo que ambos não diferiram estatisticamente dos híbridos AGX-213 (33,30\%) e AGX-217 (29,69\%). Estes resultados são explicados pela participação dos componentes colmo, folhas e panícula na estrutura física da planta, associada aos teores dos constituintes da parede celular destes componentes, os quais se relacionam intimamente aos coeficientes de DIVMS da silagem. A qualidade da fração fibrosa do compo- nente panícula do híbrido AG-2005E foi numericamente inferior à dos demais híbridos avaliados, com valores de FDN de 39,30\%, FDA de 14,79\% e $\mathrm{LIG}+\mathrm{CZ}$ de $4,68 \%$ (Tabela 2), porém a maior proporcionalidade na participação de panícula na composição da planta $(58,4 \%)$ determinou a obtenção de silagem com menor concentração de FB, o que é justificado pelos teores de FDN, FDA e LIG+CZ, os quais se mostraram superiores nos componentes colmo e folhas em relação à panícula na estrutura da planta de sorgo, independentemente do híbrido avaliado. Situação inversa foi observada na fração fibrosa do híbrido AGX-217, que apresentou no componente panícula pronunciada qualidade, com valores de $22,42 \%$ de FDN, $6,88 \%$ de FDA e $1,61 \%$ de LIG+CZ frente aos demais materiais, porém a porcentagem de panícula do híbrido AGX-217 foi inferior (31,3\%), não sendo suficiente para promover menor concentração de FB na silagem em relação ao AG-2005E.

Os valores para os coeficientes de DIVMS foram semelhantes $(\mathrm{P}>0,05)$ entre as silagens avaliadas, classificando-as, segundo Borges et al. (1997), como de média a boa qualidade. No entanto, houve tendência de maior coeficiente para o AG-2005E (57,95\%), pois este híbrido apresentou, na constituição física da planta, maior proporção de panícula $(58,42 \%)$ e folhas $(26,8 \%)$ e a menor proporção de colmo $(33,4 \%)$ em relação aos demais híbridos de sorgo avaliados. Segundo Pesce et al. (2000b), estes resultados podem explicar sua maior digestibilidade, uma vez que este genótipo apresentou a maior porcentagem da fração mais digestível da planta (folhas e panícula). Já o AG-2002 apresentou menor DIVMS (51,45\%), visto que a constituição física da planta deste genótipo se caracterizou pela baixa proporção de panícula $(24,3 \%)$ e folhas $(18,9 \%)$ e alta proporção do componente colmo (56,8\%). Durante o processo de fermentação do silo, podem ocorrer alterações significativas na DIVMS, de acordo com a constituição física percentual da planta do material ensilado. Segundo Cummins (1971), a DIVMS dos componentes físicos da planta (colmo, folhas e grãos) altera-se com o processo de ensilagem, de forma não-análoga, observando-se no componente grão aumento significativo da DIVMS, enquanto nos componentes colmo e folhas os coeficientes permanecem praticamente inalterados. Segundo Gonçalves et al. (1998), a avaliação dos coeficientes de DIVMS certamente seria melhor representada pelo resultado do consumo de alimentos e desempenho animal. 
Pereira et al. (1993), avaliando híbridos de sorgo de portes alto (AG-2002), médio (AG-2004) e baixo (AG-2005E), observaram coeficientes de DIVMS de 53,$2 ; 50,8$; e 54,3\%, respectivamente. Já Pesce et al. (2000a), trabalhando com 20 genótipos de sorgo, encontraram coeficientes de DIVMS superiores para os híbridos AG-2005E (60,0\%) e AG-2002 (57,3\%), comparados aos resultados da presente pesquisa. Segundo estes autores, o raciocínio mais correto para predizer a DIVMS da silagem baseia-se na estrutura física percentual da planta, em que a maior proporção de panícula e folhas e a menor proporção de colmo são desejadas para obtenção de maiores coeficientes de DIVMS. No entanto, ressalva-se que as proporções das diversas frações da planta não são os únicos fatores que determinam a digestibilidade. Atenção especial deve ser dada à qualidade da fibra dos híbridos de sorgo que apresentam comportamento agronômico diferenciado, quanto ao seu tipo e sua composição, considerando, de maneira geral, que a variação encontrada nos coeficientes de DIVMS da silagem esteja relacionada aos teores dos constituintes da parede celular dos componentes colmo, folhas e panícula (Tabela 2), os quais se mostraram diferentes $(\mathrm{P}<0,05)$ entre os híbridos avaliados. Segundo Zago (1991), a variabilidade genética existente nesta espécie é muito grande, indicando que o valor nutritivo da silagem de sorgo depende diretamente das características agronômicas de cada cultivar.

Os teores de nitrogênio insolúvel na FDA (NIDA), nitrogênio amoniacal no nitrogênio total (N-NH3/NT) e pH da silagem dos híbridos de sorgo são apresentados na Tabela 4. Não houve diferença $(P>0,05)$ entre os teores de nitrogênio insolúvel na FDA (NIDA), da silagem dos híbridos de sorgo, com média de 11,37\%. Segundo Oliveira (1998), se a fase aeróbia da fermentação for muito extensa, a temperatura interna do material ensilado é acrescida e, quando acima de $49^{\circ} \mathrm{C}$, contribui significativamente para aumento do teor de nitrogênio insolúvel aderido à FDA.

$\mathrm{Na}$ análise dos teores de $\mathrm{N}-\mathrm{NH}_{3} / \mathrm{NT}$ e do $\mathrm{pH}$ das silagens, os valores encontrados diferiram $(\mathrm{P}<0,05)$ entre os híbridos avaliados. A silagem do híbrido AG-2005E apresentou maior $(\mathrm{P}<0,05)$ teor de $\mathrm{N}-\mathrm{NH}_{3} / \mathrm{NT}(7,74 \%)$ e $\mathrm{pH}(4,1)$, quando comparado ao híbrido AGX-217 (6,53\% e 3,63, respectivamente), que, por sua vez, foi superior $(\mathrm{P}<0,05)$ aos híbridos forrageiros AGX-213 (3,98\% e 3,55) e AG-2002 $(3,70 \%$ e 3,55$)$, respectivamente.

$\mathrm{O} \mathrm{N}$-amoniacal, expresso em porcentagem do $\mathrm{N}$ total, indica a quantidade de proteína degradada durante a fase de fermentação ou ainda ocorrência de um aquecimento excessivo da massa no silo por reações de Maillard (Pigurina, 1991). Segundo McDonald et al. (1991), silagens mal preservadas apresentam níveis de $\mathrm{N}$-amoniacal superiores a $20 \%$ do $\mathrm{N}$ total. Esta amônia é derivada do catabolismo de aminoácidos, entre outros produtos de degradação, como aminas, cetoácidos e ácidos graxos, por via de três processos bioquímicos: deaminação, descarboxilação e reações de oxidação e redução. Os maiores teores do N-amoniacal das silagens dos híbridos AGX-217 e AG-2005E, frente aos híbridos AGX-213 e AG-2002, são explicados pela associação entre os fatores teores de MS da silagem $(32,62$ e $35,50 \%$ vs 26,79 e $29,30 \%$, respectivamente) e tipo de silo de armazenamento utilizado (tipo torta), o que determinou menor eficiência de compactação para os híbridos de

Tabela 4 - Teores de nitrogênio insolúvel na FDA (NIDA/NT, \% do $\mathrm{N}$ total ), nitrogênio amoniacal $(\mathrm{N}-\mathrm{NH} / \mathrm{NT}, \%$ do $\mathrm{N}$ total) e pH de silagens de diferentes híbridos de sorgo

Table 4 - Contents of insoluble nitrogen of $A D F(A D I N, \%$ of total $N)$ ammonia nitrogen $\left(\mathrm{N}-\mathrm{NH}_{3}\right.$, \% of total $\left.\mathrm{N}\right)$ and $\mathrm{pH}$ of silages of different sorghum hybrids

\begin{tabular}{|c|c|c|c|c|c|}
\hline \multirow[t]{2}{*}{$\begin{array}{l}\text { Parâmetros } \\
\text { Parameters }\end{array}$} & \multicolumn{4}{|c|}{$\begin{array}{l}\text { Híbridos de sorgo } \\
\text { Sorghum hybrids }\end{array}$} & \multirow[t]{2}{*}{$\begin{array}{l}\text { Média } \\
\text { Mean }\end{array}$} \\
\hline & AGX-213 & AG-2002 & AGX-217 & AG-2005E & \\
\hline $\begin{array}{l}\text { NIDA/NT } \\
A D I N\end{array}$ & $12,71^{\mathrm{a}}$ & $10,66^{\mathrm{a}}$ & $10,96^{\mathrm{a}}$ & $11,16^{\mathrm{a}}$ & 11,37 \\
\hline & $3,98^{\mathrm{c}}$ & $3,70^{\mathrm{c}}$ & $6,53^{\mathrm{b}}$ & $7,74^{\mathrm{a}}$ & 5,49 \\
\hline $\begin{array}{l}\mathrm{pH} \\
\mathrm{pH}\end{array}$ & $3,55^{\mathrm{c}}$ & $3,55^{\mathrm{c}}$ & $3,63^{b}$ & $4,10^{\mathrm{a}}$ & 3,71 \\
\hline
\end{tabular}

a,b,c Médias, na linha, seguidas por letras minúsculas diferentes, diferem entre si pelo teste de Tukey a $5 \%$.

$a, b, c$ Means, within a row, followed by different small letters, are different $(P<.05)$ by Tukey test. 
caráter duplo propósito, propiciando o surgimento de fungos (aerobiose), que resultou no aumento dos teores de $\mathrm{N}-\mathrm{NH}_{3} / \mathrm{NT}$.

Pigurina (1991) considera o $\mathrm{N}$-amoniacal como um dos principais parâmetros determinantes da qualidade da fermentação. Segundo Van Soest (1994), nas silagens que apresentam fermentações secundárias, o N-solúvel e o N-amoniacal advêm da ação de microorganismos, nos quais as concentrações desses metabólitos são conseqüência da extensão da atividade de colônias destes microorganismos em microambientes favoráveis a seu crescimento no interior do silo.

Gonçalves et al. (1999), comparando silagens de diferentes híbridos de sorgo, observaram menores concentrações de $\mathrm{N}$-amoniacal em silagens com maiores conteúdos de MS. No presente trabalho, os resultados revelaram, no entanto, que os menores teores de $\mathrm{N}$-amoniacal foram observados nas silagens de híbridos forrageiros (AGX-213 e AG-2002), os quais apresentaram menor conteúdo de MS. Porém, analisando a constituição física percentual da planta destes materiais, verificou-se menor participação de grãos na massa ensilada comparada às silagens dos híbridos AGX-217 e AG-2005E, indicando que a proteólise pode estar associada a diversos fatores, entre eles, menores quantidades de carboidratos fermentáveis (Meeske et al., 1993), menor concentração protéica (Moisio \& Heikonen, 1994), umidade de colmo e teores de tanino (Borges et al., 1997; Rodriguez et al., 1998; Gonçalves et al., 1999), pH, tempo de ensilagem e temperatura de fermentação da silagem (Rodriguez et al., 1998).

Ao considerar o $\mathrm{pH}$ das silagens, mesmo não sabendo sua velocidade de queda durante o processo de fermentação, a classificação para a silagem do AG-2005E foi como de boa qualidade. As demais silagens, por apresentarem valores de $\mathrm{pH}$ inferiores a 3,8 , foram classificadas como de muito boa qualidade. Segundo Borges etal.(1997), esta classificação não permite que as silagens sejamagrupadas de um modo simples, desde que recebam pelo menos uma classificação ruim entre os parâmetros avaliados nesta escala qualitativa.

\section{Conclusões}

A panícula é o componente da planta de sorgo que define a qualidade da silagem, por apresentar os maiores teores de MS, PB e DIVMS e menores teores de FDN, FDA, CEL e LIG+CZ, comparado ao conjunto colmo e folhas.

R. Bras. Zootec., v.31, n.1, p.302-312, 2002 (suplemento)
Com base nas características das silagens avaliadas, os híbridos de duplo propósito (AGX-217 e AG-2005E) apresentaram melhor qualidade frente aos híbridos forrageiros (AGX-213 e AG-2002).

\section{Literatura Citada}

ALMEIDA FILHO, S.L.; FONSECA, D.M.; GARCIA, R. et al. Características agronômicas de cultivares de milho (Zea mays L.) e qualidade dos componentes e da silagem. Revista Brasileira de Zootecnia, v.28, n.1, p.7-13, 1999.

ASSOCIATION OF OFFICIAL ANALYTICAL CHEMISTS AOAC. Official methods of analysis. 14.ed. Washington, D.C.: 1984. 1141p.

ASSOCIATION OF OFFICIAL ANALYTICAL CHEMISTS AOAC. Official methods of analysis. 16.ed. Washington, D.C.: 1995. 1094p.

BRASIL. Ministério da Agricultura. Levantamento de reconhecimento dos solos do Estado do Rio Grande do Sul. Recife. Departamento Nacional de Pesquisa Agropecuária-Divisão de Pesquisas Pedoloógicas, 1973. 430p. (Boletim Técnico, 30).

BORGES, A.L.C.C.; GONÇALVES, L.C.; RODRIGUEZ, N.M. et al. Qualidade de silagens de híbridos de sorgo de porte alto, com diferentes teores de tanino e umidade no colmo. Pesquisa Brasileira de Medicina Veterinária Zootecnia, v.49, n.4, p.441-452, 1997.

BRUNO, O.A.; ROMERO, L.A.; GAGGIOTTI, M.C. et al. Cultivares de sorgos forrajeros para silaje. 1. Rendimento de matéria seca y valor nutritivo da la planta. Revista Argentina Producción Animal, v.12, n.2, p.157-162, 1989.

COMISSÃO DE FERTILIDADE DO SOLO - CFRS/SC. Recomendações de adubação e calagem para os Estados do Rio Grande do Sul e Santa Catarina. 3.ed. Passo Fundo: SBCS-Núcleo Regional Sul, 1995.224p.

CUMMINS, D.G. Relationship between tannin content and forage digestibility in sorghum. Agronomy Journal, v.63, p.500-502, 1971.

DEMARCHI, J.J.A.A. Produção, valor nutritivo e características do sorgo (Sorghum bicolor L. Moench), colhido em cinco estádios de maturação, e de suas silagens. Piracicaba, SP: Escola Superior de Agricultura "Luiz de Queiroz", 1993. 230p. Dissertação (Mestrado em Zootecnia) - Escola Superior de Agricultura "Luiz de Queiroz", 1993.

DEMARCHI, J.J.A.A.; BOIN, C.; BRAUN, G. A cultura do sorgo (Sorghum bicolor L. Moench) para produção de silagens de alta qualidade. Revista Zootecnia Nova Odessa, v.33, n.3, p.111-136, 1995.

ELIZALDE, H.F. El valor nutritivo de los ensilajes. Revista Argentina Producción Animal, v.15, n.1, p.103-121, 1995.

GOERING, H.K.; VAN SOEST, P.J. Forage fiber analysis: apparatus reagents, procedures and some applications. Washington, D.C.: Agricultural Hantbook, 1970. 379p.

GONÇALVES, L.C.; BORGES, A.L.C.C.; RODRIGUEZ, N.M. et al. Silagens de sorgo de porte alto com diferentes teores de tanino e de umidade no colmo. IV - Digestibilidade in vitro da matéria seca. Arquivo Brasileiro de Medicina Veterinária Zootecnia, v.50, n.2, p.167-170, 1998.

GONÇALVES, L.C.; RODRIGUEZ, N.M.; NOGUEIRA, F.S. et al. Silagem de sorgo de porte baixo com diferentes teores de tanino e de umidade no colmo. III - Quebra de compostos nitrogenados. Arquivo Brasileiro de Medicina Veterinária Zootecnia, v.51, n.6, p.571-576, 1999. 
McDONALD, P.; HENDERSON, N.; HERON, S. The biochemistry of silage. 2.ed. Marlow: Chalcombe Publications, 1991. 339p.

MEESKE, R.; ASBELL, G.; WEINBERG, Z.G. et al. Ensiling forage sorghum at two stages of maturity with the addition of lactic bacterial inoculants. Animal Feed Science and Technology, v.43, p.165-175, 1993.

MOISIO, T.; HEIKONEN, M. Lactic acid fermentation in silage preserved with formic acid. Animal Feed Science and Technology, v.47, p.107-124, 1994.

MORENO, J.A. Clima do Rio Grande do Sul. Porto Alegre: Secretaria da Agricultura. 1961. 41p.

NUSSIO, L.G. Produção de silagem de alta qualidade. In: REUNIÃO NACIONAL DE MILHO E SORGO, 19., 1992, Porto Alegre. Anais... Porto Alegre: Secretaria de Agricultura e Abastecimento, 1992. p.155-175.

NUSSIO, L.G. Milho e sorgo para produção de silagem. In: PEIXOTO, A.M. et al. (Ed.) Volumosos para bovinos, 2.ed. Piracicaba: Fundação de Estudos Agrários "Luiz de Queiroz”. 1995. p.75-177.

OLIVEIRA, J.S. Produção e utilização de silagem de milho e sorgo. Juiz de Fora: EMBRAPA-CNPGL, 1998. 34p. (EMBRAPA-CNPGL. Circular Técnica, 47).

PEREIRA, O.G.; OBEID, J.A.; GOMIDE, J.A. et al. Produtividade de uma variedade de milho (Zea mays L.) e de três variedades de sorgo (Sorghum bicolor (L.) Moench) e o valor nutritivo de suas silagens. Revista Brasileira de Zootecnia, v.22, n.1, p.31-38, 1993.

PESCE, D.M.C.; GONÇALVES, L.C.; RODRIGUEZ, N.M. Porcentagem, perda e digestibilidade in vitro da matéria seca das silagens de 20 genótipos de sorgo. Arquivo Brasileiro de Medicina Veterinária Zootecnia, v.52, n.3, p.250-255, 2000a.

PESCE, D.M.C.; GONÇALVES, L.C.; SANTOS, J.A. et al. Análise de vinte genótipos de sorgo (Sorghum bicolor(L.) Moench), de portes médio e alto, pertencentes ao ensaio nacional. Revista Brasileira de Zootecnia, v.29, n.4, p.978-987, 2000 b.

PIGURINA, G. Factores que afectan el valor nutritivo y la calidad de fermentacion de ensilajes. In: Pasturas y producción animal de áreas organaderia intensiva. Montevideo: Instituto Nacional de Investigacion Agropecuária, 1991. p.77-92. (Serie Tecnica, 15)

PIZARRO, E.A. Sorgo - Produção de silagem. Informe Agropecuário, v.5, n.56, p.48-51, 1979.
RODRIGUEZ, N.M.; BORGES, A.L.C.C.; GONÇALVES, L.C. et al. Silagem de sorgo de porte alto com diferentes teores de tanino e de umidade no colmo. III - Quebra de compostos nitrogenados. Arquivo Brasileiro de Medicina Veterinária Zootecnia, v.50, n.2, p.161-165, 1998.

SAS INSTITUTE. SAS Language reference. Version 6, Cary, NC: 1993. 1042p.

SILVA, F.F.; GONÇALVES, L.C.; RODRIGUEZ, J.A.S. et al. Qualidade de silagens de híbridos de sorgo (Sorghum bicolor (L.) Moench) de portes baixo, médio e alto com diferentes proporções de colmo+folhas/panícula. 1. Avaliação do processo fermentativo. Revista Brasileira de Zootecnia, v.28, n.1, p.14-20, 1999a.

SILVA, F.F.; GONÇALVES, L.C.; RODRIGUEZ, J.A.S. et al. Qualidade de silagens de híbridos de sorgo (Sorghumbicolor (L.) Moench) de portes baixo, médio e alto com diferentes proporções de colmo+folhas/panícula. 2. Avaliação do valor nutritivo. Revista Brasileira de Zootecnia, v.28, 1, p.21-29, 1999b.

SILVA, L.F.P.; MACHADO, P.F.; FRANCISCO Jr., J.C. et al. Características agronômicas e digestibilidade in situ da fração volumosa de híbridos de milho para silagem. Scientia Agrícola, v.56, n.1, p.171-183, 1999c.

TILLEY, J. M.; TERRY, R. A. A two-stage technique for the in vitro digestion of forage crops. Journal British Grassland Society, v.18, p.104-111, 1963.

VAN SOEST, P.J. Nutritional ecology of the ruminant. 2.ed. Ithaca: Cornell University Press, 1994. 476p.

ZAGO, C.P. Cultura do sorgo para produção de silagem de alto valor nutritivo. In: PEIXOTO, A.M.; MOURA, J.C.; FARIA, V.P. (Ed.) SIMPÓSIO SOBRE NUTRIÇÃO DE BOVINOS, 4., 1991, Piracicaba. Anais... Piracicaba: Fundação de Estudos Agrários "Luiz de Queiroz”, 1991. p.169-217. 